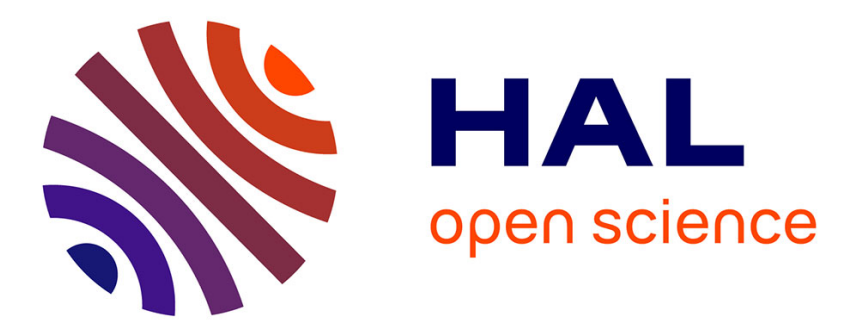

\title{
HCI as an instrument for strengthening culture and language of a Colombian native community
}

Annabelle Boutet, Franck Poirier, Gilles Coppin, Santiago Rincon, Tulio Rojas Curieux

\section{To cite this version:}

Annabelle Boutet, Franck Poirier, Gilles Coppin, Santiago Rincon, Tulio Rojas Curieux. HCI as an instrument for strengthening culture and language of a Colombian native community. HCI International 2011, 2011, Orlando (FL), United States. pp.556-565, 10.1007/978-3-642-21660-2_63 . hal-00816603

\section{HAL Id: hal-00816603 \\ https://hal.science/hal-00816603}

Submitted on 25 May 2013

HAL is a multi-disciplinary open access archive for the deposit and dissemination of scientific research documents, whether they are published or not. The documents may come from teaching and research institutions in France or abroad, or from public or private research centers.
L'archive ouverte pluridisciplinaire HAL, est destinée au dépôt et à la diffusion de documents scientifiques de niveau recherche, publiés ou non, émanant des établissements d'enseignement et de recherche français ou étrangers, des laboratoires publics ou privés. 


\title{
Human-Computer Interaction as an Instrument for Strengthening Culture and Language of a Colombian Native Community
}

\author{
Santiago Ruano Rincón ${ }^{1,3}$, Annabelle Boutet ${ }^{1,3}$, Gilles Coppin ${ }^{1,3}$, Franck \\ Poirier $^{2,3}$, and Tulio Rojas Curieux ${ }^{4}$ \\ 1 Institut Télécom - Télécom Bretagne - UMR CNRS 3192 Lab-STICC - France \\ ${ }^{2}$ Université de Bretagne-Sud - Laboratoire VALORIA - Vannes, France \\ 3 Université européenne de Bretagne, France \\ ${ }^{4}$ Universidad del Cauca - Grupo de estudios lingüísticos, pedagógicos y \\ socioculturales - Popayán, Colombia \\ \{santiago.ruano-rincon, annablle.boutet, gilles.coppin\}@telecom-bretagne.eu, \\ franck.poirier@univ-ubs.fr, trojas@unicauca.edu.co
}

\begin{abstract}
This paper is about the relationship between culture and human-computer interaction. Cultures are live, open and in continuous change. Computer and information technology, as external factors for non-Western-industrialized societies, may trigger transformations, that sometimes, could be considered as negative or unwanted. For example, the usage of Western word-processors modified the Japanese writing system when Japanese people faced a number of unfamiliar concepts introduced in those computer tools [8]. At the same time, minority societies around the world are in danger of extinction. The Nasa people, our target population, struggle to revitalize their mother tongue and cultural traditions. This text presents an experience about developing or adapting computer tools to help the revitalization efforts. The use of the computer could lead to positive effects, or at least, to effects aligned with the policies of the society.
\end{abstract}

Keywords: Culture, Language and culture preservation, Nasa native community, HCI.

\section{Introduction}

The main motivation of the project presented in this paper is the impact that HCI and the culture of users may have on each other. We believe that it is a reciprocal relationship, with repercussions in both directions: the development and use of a certain technology is impacted by the users' culture, while, technology may modify cultural characteristics of a society. Through this project, we aim to develop computer tools for a Colombian indigenous community, called Nasa. As technology providers, we would like to avoid, in our users' context, a similar impact to the modifications suffered by the Japanese writing system when "Western" word-processors were introduced in Japan. Furthermore, we would 
like to take advantage of the possible power of transformation of digital devices. Thus, we address this effort to support the campaigns and policies of the Nasa community to revitalize their language and traditions.

Language-oriented processes seem to be insufficient. An earlier experience showed that the translation of the main computer interface into the Nasa language was highly complex and unsuitable for that time 2]. Internationalization/localization processes commonly used for other languages and contexts were unfruitful when dealing with the Nasa language. That experience also concluded that the adaptation or the development of information tools should be done taking into account other cultural particularities. Our first challenge was to comprehend this culture, and select from it the elements that may have an impact on interaction with computers.

Before going any further, we need to come to an agreement about what we understand by "culture." For the moment, we take the definition proposed by Hofstede [6], and used by Hoft in her HCI and Culture-related work 7]. For them, culture is "learned behavior consisting of thoughts, feelings, and actions." Thus, developers should have an understanding of how their users might think, feel and react to their products And further, how their products would affect the environment and context of users.

To achieve our goal, we need to understand the Nasa context, from its social, educational and even political perspectives. Through the paper, we briefly describe our apprehension about the Nasa culture. We introduce the community in the following section, then, we present a short outline of culture and HCI-related work. In sections 4 and 5 we briefly describe our approach: our development framework, based on the design of three different tools, and the cultural characteristics that have impacted them. Finally, we present some user reactions and conclusions.

\section{The Nasa People}

The Nasa people 1 are an indigenous community of the Colombian territory. To be more precise, they inhabit the Southwestern Andes of the country, in the section crossing the Cauca department. There, they live in resguardos 2 , communal lands of collective ownership, where Colombian indigenous people can exercise their traditional activities. For most of the Nasa, agriculture is the main economic and living activity. Different kinds of products, such as maize, coffee, potatoes, and sugar cane are produced thanks to the diversity of temperatures found in the mountains [16].

These mountains have helped to preserve the Nasa's mother tongue: Nasa Yuwe. A unique and complex language, that seems to have no clear relationship with the other 60 native languages exiting in Colombia today. It is important to

${ }^{1}$ The Nasa are also know as Paez, as they were named by the Spanish. We prefer to use the name they use when referring to themselves.

${ }^{2}$ Resguardos: The Colombian Constitution grants some rights to native communities over these special territorial units. 
note that the Nasa were, until recently, an oral-tradition society. As far as we know, there is no evidence of writing systems produced by Amerindian communities before the arrival of Europeans on the American continent. In the case of the Nasa Yuwe, the current writing system was approved by the community in 2001, as the product of the unification process of three different efforts to give the Nasa people an alphabet. It is a rich alphabet based on Latin, formed by 32 vowels and 37 consonants, which is now learned by children in schools. From our point of view, it could be seen as a strategy for preserving this language: now, they can write their own history in their own language.

According to the number of speakers, the Nasa Yuwe is the second language in the country. From around 150,000 people, i.e. the whole Nasa population, two thirds speak the language. Sadly, this number decreases from time to time, especially among young people. According to interviews carried out in the Resguardo de Novirao, adults consider that factors such as a lack of teaching, a lack of importance, social stigma and the influence of technology are some of the reasons why people no longer speak Nasa Yuwe3.

The Regional Indigenous Council of Cauca (CRIC), the main indigenous organization in the region, and its Education Program (PEBI), manage most of schools in the north of the Cauca department. Among their policies, they demand the revitalization of Nasa Yuwe and Nasa traditions through school [3]. They seek to provide bilingual education, focused on agricultural activities, taking into account the Nasa traditions and methods.

We will show other characteristics of this culture when we describe our work in the following sections.

\section{Related Work}

Culture in HCI is a topic that has been taken up in recent years. Since 1996, Elisa del Galdo and Jakob Nielsen identified some cultural issues and variables taken into account by most international products in that time, such as: language, format of dates and numbers, character sets and notations, among others 5 . Such variables, according to the Iceberg Model presented by Nancy Hoft [7, are visible and easy to study by an external observer, since they are "above the surface." However, del Galdo and Nielsen proposed to explore more levels of software localization.

To go below the surface of the Iceberg, and take into account other cultural variables, Hoft proposes the elaboration of a Cultural Model. Since then, some work has been done [12, including a model for "cross cultural game design" [1]. However, Heike Winschiers-Theophilus affirms that current Cultural Models are missing the impact of culture on some stages of the whole design process [19]. We have developed our version of a Cultural Model [17, that is briefly outlined in this paper.

From a lower level point of view, issues found during interaction between different cultures through the interfaces are clearly explained by semiotics.

\footnotetext{
${ }^{3}$ Personal communication, with Marta Corrales and Tulio Rojas, 2010.
} 
Computer interfaces are full of signs, such as words, icons, movements, actions, among others, that make possible the human-computer interaction, and whose interpretation largely depends on the users' culture. According to the Semiotic Engineering theory, proposed by Clarisse de Souza [4, HCI is a Metacommunication process, between (a deputy of) the developer and the user. As a consequence, the developer must need to talk the same "language" as the user, selecting suitable signs in the interface design.

Our experience with the Nasa people has driven us towards the development of educational tools for children from that culture. The work of Matthew Kam, Anuj Kumar et al. [911] seems to be the most exhaustive and serious about mobile games design for kids in a rural context. We take some elements from their work, such as the strategies to observe local games and extract from them suitable information to design computer tools. Medhi et al. have done an interesting work on Text-Free interfaces for illiterate and semi-illiterate users in Bangalore slums [13. We have found a couple of similar observations about users' behavior and preferences that we will describe on the text.

Among the work specifically designed for the Nasa people, we found the "Web community to support Nasa ethno-education processes"' 4 . It seems that there exist other isolated efforts, for which we have not been able to find documentation.

\section{Our Development and Application Framework}

At present, the "tangible" outcomes of the experience described in this paper have been the development processes of three tools, focused on Nasa children and their schools. While the first has reached maturity, the other two are in their first development cycle:

1. Çut pwese'je, the maize game

2. Çxuga pwese'je, the spinning top game

3. and, the design of a "global" interface, as an alternative to the Desktop Metaphor.

The main objective of the maize game is to help Nasa children (and adults) to learn the Nasa Yuwe alphabet, identifying its 69 graphemes 5 . It is a hangman-like game adapted to the Nasa context. Instead of a condemned man, çut pwese'je's central stimulus is a field of maize plants, main staple of the Nasa diet [17].

The second tool, çxuga pwese'je, is planned to be a competitive game where four children have to make their spinning tops spin for as long as possible. To do so, they have to continuously solve challenges in Nasa Yuwe. However, we have not been able yet to determine the adequate type of questions. We have thought

\footnotetext{
${ }^{4}$ Comunidad virtual de apoyo a los procesos de etnoeduación nasa: http://www.ewa.edu.co

${ }^{5}$ Grapheme: the unit of a writing system. Nasa Yuwe has graphemes of one, two and three letters, i.e: îh, aa, çx, pxh.
} 


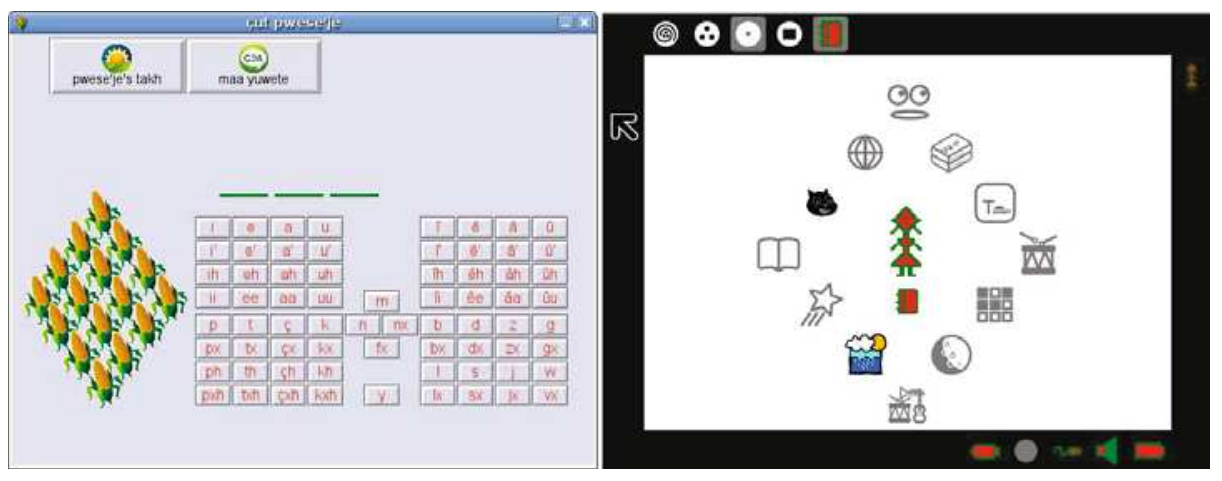

Fig. 1. Cut pwese'je, the maize game (left). Individual space in our adaptation of the Sugar learning environment (right).

about asking for arithmetic operations in the Nasa language, but the way they should be done is still unclear, and linguistic research is needed first.

Besides these two tools, we have also looked for an alternative interface to the Desktop Metaphor, to be used in the computers of Nasa schools. According to the designs made collectively with Nasa students and teachers, we have decided to adapt the Sugar learning environment, which offers an alternative to traditional office-desktop software. It has been originally developed for the OLPC XO-1 laptop computer and is now supported and maintained by Sugar Labs 6 .

\subsection{Development Processes}

The design of the maize game started in 2006, then it followed an iterative process. Each cycle allowed us to comprehend Nasa characteristics, through the design and evaluation of prototypes. The three current cycles are described in [17.

The spinning top game and the global metaphor have been designed collectively with students and teachers in two Nasa schools. During an in-field workperiod in the resguardos de Tumbichucue and Caldono, we used blackboards and chalks to design and evaluate the tools' dynamic.

The spinning top game was inspired from local games, played by children in their resguardos. The ideas of Matthew Kam were useful in this design 9111. We had the chance to observe different games during a celebration day in Tumbichucue. Rustic and accessible material is used to build different types of spinning tops, carts, and other toys. The spinning tops game is based on phçxukwe çxuga: kids have to repeatedly strike a wooden spinning top with a small fiber whip to make it spin as long as possible. As expected, during a competition, the goal is to make it turn more than the others. At the time of the observations, the local record in Tumbichucue was $1 \mathrm{~h} 40 \mathrm{~m}$.

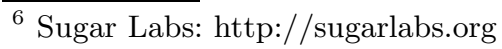



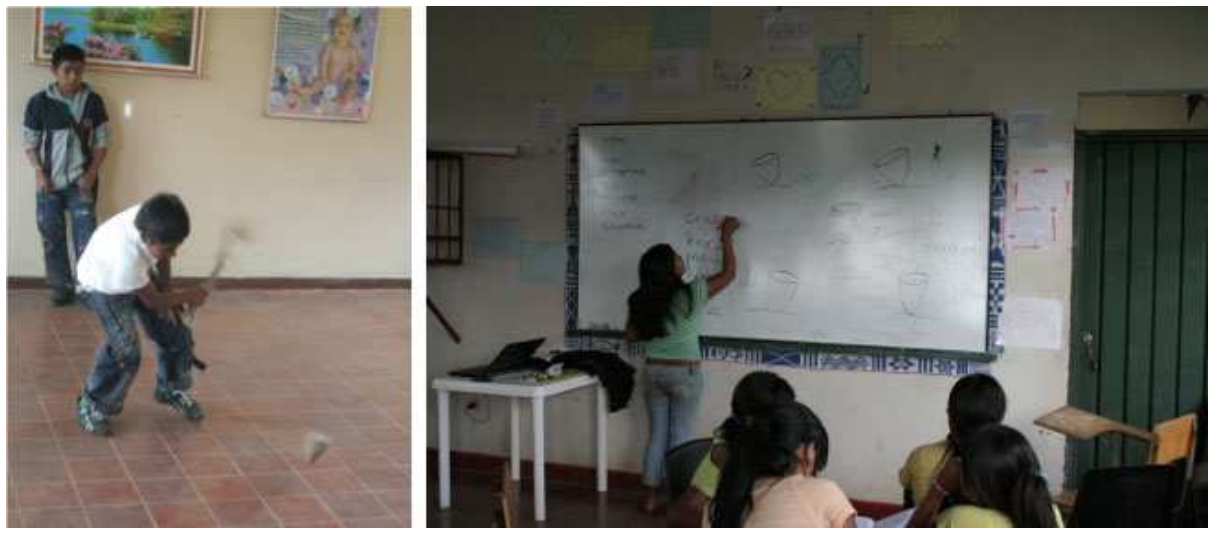

Fig. 2. Nasa kid playing with a spinning top during a competition in the Tumbichucue (left). Collective evaluation of the design of the spinning top game in Caldono (right).

\section{Cultural Dimensions}

Through our experience, we have encountered some questions that have directed our research: How to study our target culture?, How to select relevant characteristics that would impact the design and usage of computer interfaces?, How to apply them to the design of human-computer interaction? and Is it possible to highlight them through interaction?

Nancy Hoft deals with similar questions and suggests the modeling of culture as a strategy to answer them [7]. Following her recommendations, we have developed a Cultural Model based on the work of Kluckholm and Strodtbeck [10], Hofstede 6, Victor [18, among others. Our proposal takes into consideration six wide cultural variables for the development of computer tools: Language, Space, Environment and technology, Social organization, Notion of time and Nonverbal signs. These characteristics and their relationship with the development of the maize game are described in [17. This model was later evaluated through the design processes of the game of the spinning top and the global interface.

In this section, we summarize our observations about each characteristic, and how they have impacted the tool development processes.

\section{$5.1 \quad$ Language}

Besides the lack of a basic computer glossary in Nasa Yuwe, we have encountered other language-related challenges. For example, the lack of some Nasa Yuwe characters in available keyboards meant we had to look for a graphical input method for çut pwese'je, described in [17]. The current keyboard layout is based on the order in which kids learn the alphabet. The four groups-by-four groups organization is taken from the concept of the rhombus and its relationship with the number four (See Figure 1). 
Moreover, we have proposed to use the spinning top game as a tool to help children learn arithmetic operations in Nasa Yuwe. However, we have found that it is still unclear, among linguists, how these operations are done. As far as we know, current bibliographic reference about numbers in Nasa Yuwe is limited to numbering [15]. Thus, further research is needed.

\subsection{Space Structuring}

Interfaces may have an essential spatial component, such as the Desktop, used in the common computer interface. We base our alternative interface design on different levels of Nasa space structuring, such as the hearth (tulpa), the house garden $(t u l)$ and the resguardo.

We think that a "collective space" in the interface would fit the collectiveorientation that we think is present in the Nasa culture (see below). Thus, we could take advantage of networking capabilities and make it possible to collectively work through computers. For that, we propose an analogous interface to the hearth (tulpa). The Nasa three-stones tulpa is the central point of "traditional" houses. It is a place where family and close friends spend time together, especially after work journeys. During a collective design session, Nasa students and teachers also proposed to include a metaphor with the resguardo, to expand the area of interaction and be able to work with the whole community.

\subsection{Environment and Available Technology}

The Nasa context is mostly agricultural, so files, folders, desktops, trash bins and the concept of recycling are uncommon in this rural environment. The Desktop Metaphor's foundations are inconsistent with the Nasa mind set, resulting in a misunderstood metaphor by the Nasa people [2]. Our tools have been designed with the help of studens and teachers, taking into account the local environment and available material: maize, local toys, space structures, among others.

On the other hand, available technology imposes limitations and conditions the design. To cite two examples: the scarce equipment found in schools strengthens the necessity of sharing a single computer among several children, and the absence of Internet makes it unsuitable to create online tools. However, some computer rooms are equipped with local networks, which make it possible to design networked applications.

\subsection{Social Organization}

The social organization is a cultural dimension that embraces a wide range of variables. Here, we expose two of them: the educational context and the community-orientation.

Educational context. Since we focus on Nasa children and their schools, we needed to understand the particularities of the educational context. Nasa authorities aim to provide bilingual education, in Nasa Yuwe and Castilian, centered on agricultural activities and communal policies. 
Community-orientation. It is manifested in, at least, two different aspects: territory and work preferences. The Nasa people live in resguardos, communal and inalienable lands that allow collective ownership. Furthermore, there exist three Nasa traditional types of collective work, more valued than other individual ways of working [14. Therefore, the community is involved in a wide range of aspects of the Nasa way of living, from the construction of a new classroom, to the debate about the creation of a writing system for Nasa Yuwe [16]. Consequently, we have introduced our projects publicly and had more fruitful designs and evaluations when they were run collectively than with one single individual.

Likewise, we seek to highlight the communal character design tools that encourage the collective use of one single device. For example, the spinning top game is designed for up to four simultaneous players.

\subsection{Notion of Time}

Usability evaluation methods such as Thinking aloud, quantitatively measure time of task completion to evaluate the quality of an interface. However, as Winschiers has found in Namibia, we think that the Nasa people give a minor importance to the time. In a general rule, they would not care to spend a "huge" quantity of time to answer a question in our games. Consequently, we have avoided time limits in their design.

\subsection{Non-verbal Signs}

The rhombus and the spiral are important Nasa symbols, representing, among other concepts, one World view and time/life development, respectively. We use such symbols as layouts, metaphors and other interaction signs. The rhombus is easily visible in both prototypes of Figure 1.

We use the spiral and its relationship between the different social interaction levels, to link the tulpa and resguardo analogies in the interface.

\section{User Reactions}

For the moment, we have evaluated our work through qualitative observations of user reactions, which outcome is to summarized here.

"Collectively" works better. Our initial evaluations of the maize game were individually run, using "thinking aloud" based methods. However, kids seemed to be uncomfortable. They called other people around to join in the evaluation, which seemed to be a more natural way. From that moment, designs and evaluations were done collectively. Winschiers [19] and Medhi [13] have found similar reactions in Namibia and India, respectively.

Abstract ideas. Nasa people seem to be uncomfortable with abstract ideas, such as disappearing maize plants, used to describe the maize game dynamic, or plants 
with eyes and nose, intended to be attractive for Nasa kids. When testing the game, a kid said "oh, those bad birds!", when he saw the first maize pop up. Teachers and kids have suggested that it would be better that an animal steals the maize when the user is wrong. Medhi also reports similar observations in this point [13].

Good reception. During the design evaluation using the blackboard or when playing with the maize game on the computer, children (and adults) laughed and made jokes about other players' answers. However, they show excitement and concentration when it was their turn. Most people clearly wanted to solve Nasa Yuwe challenges and to write "complex" concepts in their language, especially during the design of the spinning top game.

Moreover, several mayores 7 have expressed their interest in building a physical keyboard like the graphical one used in the maize game.

\section{Conclusions}

HCI Researchers have concluded that other cultural dimensions than language have to be taken into account in the design and development of computer tools. In our project, we have considered other variables, such as: Space structuring, Environment and Technology, Social organization, Notion of time and Nonverbal signs to construct tools for the schools of the Nasa Colombian native community.

Some of these dimensions might impact not only the interface itself, but also processes like development and evaluation, or even the usage practices. For example, the collectivist character of the culture has improved the development of the tools, students and teachers have collectively participated in the design, evaluated and provided new ideas.

Finally, with those tools we aim at helping in revitalisation efforts of language and culture. We hope that the inclusion of cultural variables in the interaction will help to give value to the culture, and reduce, for example, the social stigma felt by some native people when using their mother tongue.

\section{Acknowledgments}

This work has been possible thanks to the Institut Télécom and its foundation. We would like to thank Abelardo Ramos, Nasa leader and linguist, whose help has been essential. As well as the resguardos of Tumbichucue and Caldono, who kindly accepted to receive and work with us. The founding of the Université Européenne de Bretagne and its International Doctoral College made it possible to carry out the in-field work in 2010. Special thanks to Mary Daley for reviewing the writing of this paper.

$\overline{7}$ Mayores: Elders, people considered as wise by the community. 


\section{References}

1. Chakraborty, J., Norcio, A.F.: Cross cultural computer gaming. In: Aykin, N. (ed.) IDGD 2009. LNCS, vol. 5623, pp. 13-18. Springer, Heidelberg (2009)

2. Checa Hurtado, Á., Ruano Rincón, S., et al.: Guidelines for the development of graphical user interfaces suitable for the Nasa Colombian indigenous community. In: Proc. HFT 2006. ETSI (2006)

3. Consejo Regional Indígena del Cauca - CRIC, Rappaport, J.: ¿Qué pasaría si la escuela...? 30 años de construcción de una educación propia. Fuego Azul, Bogotá (2004)

4. de Souza, C.S.: The Semiotic Engineering of Human-Computer Interaction. MIT Press, Cambridge (2005)

5. del Galdo, E.M., Nielsen, J. (eds.): International users interface. John Wiley \& Sons, Inc., New York (1996)

6. Hofstede, G., Hofstede, G.J.: Cultures and Organizations: Software of the Mind. McGraw-Hill, New York (2005)

7. Hoft, N.: Developing a cultural model. In: International User Interfaces. John Wiley \& Sons, New York (1996)

8. Ito, M., Nakakoji, K.: Impact of culture on user interface design. In: International User Interfaces. John Wiley \& Sons, New York (1996)

9. Kam, M., Mathur, A., Kumar, A., Canny, J.: Designing digital games for rural children: a study of traditional village games in india. In: Proc. CHI 2009. ACM, New York (2009)

10. Kluckhohn, F., Strodtbeck, F.: Variations in value orientations. Row, Peterson (1961)

11. Kumar, A., Tewari, A., Shroff, G., Chittamuru, D., Kam, M., Canny, J.: An exploratory study of unsupervised mobile learning in rural india. In: Proceedings CHI 2010. ACM, New York (2010)

12. Marcus, A., Gould, E.: Cultural dimensions and global web user-interface design. what? so what? now what. In: Proc. 6th Conference on Human Factors and the Web (2000)

13. Medhi, I., Sagar, A., Toyama, K.: Text-free user interfaces for illiterate and semiliterate users. In: International Conference on Information and Communication Technologies and Development, ICTD 2006, pp. 72-82 (May 2006)

14. Ximena Pachón, C.: Los Nasa o la Gente Páez. In: Geografía humana de Colombia - Región Andina Central, vol. 2, ch. 2. Instituto colombiano de cultura hispánica, Bogotá (1996), http://www.banrep.gov.co/blaavirtual/geografia/-geohum2/indice.htm

15. Ramos Pacho, A.: Numeración y neonumeración en nasa yuwe. Revista Çxayu'çe: Semillas y mensajes de etnoeducación. Número 9 - PEBI-CRIC, n.d.

16. Rojas Curieux, T.: Desde arriba y por abajo construyendo el alfabeto nasa. La experiencia de la unificación del alfabeto de la lengua páez (nasa yuwe) en el Departamento del Cauca - Colombia (2002), http://lanic.utexas.edu/project/etext/llilas/cilla/rojas.html

17. Ruano Rincón, S., Coppin, G., Boutet, A., Poirier, F., Rojas Curieux, T.: Designing for Other Cultures: Learning Tools Design in the Nasa Amerindian Context. In: Human-Computer Etiquette: Cultural Expectations and the Design Implications They Place on Computers and Technology. Auerbach Publications (2010)

18. Victor, D.: International Business Communication. HarperCollins, New York (1992)

19. Winschiers-Theophilus, H.: The art of cross-cultural design for usability. In: Stephanidis, C. (ed.) UAHCI 2009. LNCS, vol. 5614, pp. 665-671. Springer, Heidelberg (2009) 